\title{
Greenhouse gas emissions of UK diets
}

\author{
R.L. Bates, N.G. Chambers and L.C.A. Craig \\ The Rowett Institute, The University of Aberdeen, Aberdeen, AB25 2ZD.
}

A move to a more sustainable diet has been promoted as a way to reduce the impact of human activities on the planet ${ }^{(1)}$ and improve population health ${ }^{(2)}$. Food consumption is responsible for up to $30 \%$ of the environmental impact of households ${ }^{(3-4)}$. Diet-associated GHGE (greenhouse gas emissions) have been estimated in several studies, however, very few have estimated them from diets recorded by consumers themselves (self-selected diets) ${ }^{(5)}$. The aim of this study was to update estimates of diet-associated GHGE ${ }^{(6-7)}$ for the whole of the UK population using self-selected diets from years 1-6 of the NDNS ${ }^{(8)}$ by developing a new GHGE database for all foods in the NDNS food nutrient database.

GHGE data for individual foods and dishes were matched to NDNS nutritional tables. Where a GHGE value for a specific item was not available, reasonable substitute data was used based on similarities in food type and composition. Mean daily GHGE per person were estimated for all individuals in the NDNS (years 1-6). Percentage contribution of food groups to mean daily GHGE was calculated using the NDNS food groups. Statistical significance between demographic groups was tested using ANOVA and general linear model. Statistical significance level from two-sided hypotheses was set at $\mathrm{P} \leq 0 \cdot 05$. NDNS data was obtained from the UK Data Archive.

GHGE data were matched to $91 \%$ of the individual foods or food products in the NDNS.

For the UK population the mean individual daily diet-associated GHGE ranged from 170 to $13,673 \mathrm{gCO}_{2} \mathrm{e} / \mathrm{d}$. Adults had significantly higher mean GHGE than children (under 18 years) for both males 4,273 $\mathrm{gCO}_{2} \mathrm{e} / \mathrm{d}$ (range $354-13,673$ ) vs $3,149 \mathrm{gCO} 2 \mathrm{e} / \mathrm{d}(\mathrm{ran}-$ ging from 658 to 9,043) and females $3,364 \mathrm{gCO}_{2} \mathrm{e} / \mathrm{d}$ (range $532-8,483$ ) vs 2,765 $\mathrm{gCO}_{2} \mathrm{e} / \mathrm{d}$ (ranging from 170 to 9,996) (Table). GHGE was significantly different between males and females $(\mathrm{P} \leq 0.001)$.

Table 1.

\begin{tabular}{|c|c|c|c|c|c|}
\hline & \multicolumn{2}{|l|}{ Male } & \multicolumn{2}{|l|}{ Female } & \multirow[b]{2}{*}{$P_{\text {between se: }}$} \\
\hline & $\begin{array}{c}\text { Mean GHGE } \\
\left(\mathrm{gCO}_{2} \mathrm{e} / \mathrm{d}\right)\end{array}$ & $\mathrm{N}$ & $\begin{array}{c}\text { Mean GHGE } \\
\left(\mathrm{gCO}_{2} \mathrm{e} / \mathrm{d}\right)\end{array}$ & $\mathrm{N}$ & \\
\hline Under 7 years & 2492 (627) & 845 & $2397(628)$ & 778 & 0.002 \\
\hline $7-10$ years & $3142(729)$ & 496 & 2895 (771) & 472 & $<0.001$ \\
\hline $11-14$ years & 3507 (938) & 508 & $2981(814)$ & 484 & $<0.001$ \\
\hline $15-18$ years & 4007 (1240) & 504 & 3047 (908) & 549 & $<0.001$ \\
\hline $19-50$ years & $4426(1408)$ & 1030 & 3344 (1016) & 1549 & $<0.001$ \\
\hline Over 50 years & 4105 (1230) & 916 & 3318 (923) & 1243 & $<0.001$ \\
\hline$P_{\text {between age group }}$ & $<0.001$ & & $<0.001$ & & \\
\hline
\end{tabular}

Meat and dairy were the major contributors to the GHGE associated with UK diets. In adults, this was from beef dishes (9\%) and in children (under 18 years) chicken dishes $(6 \%)$. The contribution of beef dishes increased with age. Between males and females beef dishes contributed similarly to GHGE $(8 \%)$.

This study is unique in estimating dietary GHGE across the population including children and one of the first studies to include all the food groups in the diet. If we are to reduce dietary GHGE in line with recommendations, we need to understand the patterns of existing consumption.

1. IPCC (2014) Climate Change 2014: Impacts, Adaptation, and Vulnerability. Geneva: IPCC.

2. FAO (2011) Biodiversity and Sustainable Diets United against Hunger November 3-5 FAO Headquarters, Rome Rome: Food and Agriculture Organization

3. Notarnicola B, Tassielli G, Renaulli PA et al. (2017) J Clean Prod 140, 753-765.

4. EC (2006) Eur Comm Tech Rep EUR 22284:139.

5. Perignon M, Vieux F, Soler L-G et al. (2017) Nutr Rev 75, 2-17.

6. Green R, Milner J, Dangour AD et al. (2015) Clim Change 129, 253-265.

7. Horgan GW, Perrin A, Whybrow S et al. (2016) Int J Behav Nutr Phys Act 13, 46.

8. Public Health England (2017) https://www.gov.uk/government/statistics/national-diet-and-nutrition-survey-results-from-years-1-to-4-combined-ofthe-rolling-programme-for-2008-and-2009-to-2011-and-2012 (accessed July 2017). 